\title{
Digitalization of Rural Communities
}

\section{Radhika Kapur*}

Pedagogy and Organizational Culture in Nursery Schools, Delhi University, New Delhi, India

*Corresponding Author: Radhika Kapur, Pedagogy and Organizational Culture in Nursery Schools, Delhi University, New Delhi, India.

Received: July 15, 2019; Published: August 20, 2019

DOI: $10.31080 / A S A G .2019 .03 .0627$

\begin{abstract}
In India, in rural communities, the individuals are still residing in the state of backwardness and are overwhelmed by the conditions of poverty, illiteracy and unawareness. It is necessary for the development of rural communities, to generate awareness among individuals in terms of digitalization and use of technologies. The main objective of this research paper is to understand the meaning and significance of digitalization of rural communities and how they have proven to be advantageous to the rural individuals. In the present existence, there have been formulation of measures and programs that are promoting digitalization of rural communities. Furthermore, the rural individuals have generated awareness in terms of the fact that when they will recognize the significance of education and learn to make use of technologies, they will be able to bring about improvements in their lives. Through digitalization of rural communities, there have been improvements in governance and management, education, health care facilities, transportation, agriculture, farming practices, infrastructure and so forth. Furthermore, the individuals are able to make improvements in their livelihoods opportunities. The main concepts that have been taken into account in this research paper include, concept of digitalization in rural areas, benefits of digital India program, digital India and empowerment of rural communities, estimated impact of digital India by 2019 and problems and challenges.
\end{abstract}

Keywords: Challenges; Digitalization; Empowerment; Livelihoods Opportunities; Rural Communities; Technologies

In India, more than 70 percent of the population resides in rural communities. For leading to progression of individuals, communities and nation, there is a need to make efforts that are dedicated towards promoting development of rural communities. The Government of India has made considerable efforts, such as the Digital India Campaign, which was initiated in 2015. The main objective of this campaign is to cause reduction in the digital India divide and Information and Communications Technologies (ICT) has proven to be a tool that has led to its successful implementation [1]. Digital India is a national program, which focuses upon providing universal digital literacy and universal accessibility of all digital resources to the citizens. The vision is focused upon three main aspects, i.e. creation of digital infrastructure, delivery of governance and services on demand and digital empowerment of citizens. Digital India program focuses upon restructuring of several existing schemes to lead to transformation [2].

The vision of the program has led to transformation of the country into a digitally-empowered society and knowledge economy through infrastructural reforms, such as, high speed internet in all gram panchayats, lifelong digital identification for all citizens, mobile banking for all, accessibility to Common Service Centres
(CSC), shareable private spaces on an easily accessible public cloud and cyber security. The program will also ensure that all government services and information will be available anytime, anywhere and on any device that is easy to use, available on a major scale and is safe. It is one of the major steps that has been initiated by the Government to motivate and connect the Indian economy. The program symbolizes the vision of the Government of India to establish connection between citizens of India and promote empowerment opportunities among them. Under the Digital India Program, technology will render a significant contribution in achieving the effective, manageable and economical governance [2].

\section{Concept of digitalization in rural areas}

The concept of digitalization in rural areas have focused upon creating an increased internet connectivity, which have enabled the rural individuals to generate awareness in terms of various aspects and facilitated improvements in their living conditions. The establishment of vision to create a digital economy have enabled the individuals to bring about improvements in various areas and promote transformations. The main aspects, which have recognized the significance of digitalization in rural communities have been stated as follows: [2]. 
- Broadband Highways: Web based portals and mobile apps will be developed to access online information, while one is travelling. High speed broadband highways will be provided through fibre optics that connects all the remote areas, government departments, universities, R\&D and so forth.

- Universal Mobile Access: With the initiation of digital India program, the nation is ready to be well-connected, efficient and more productive in every aspect. Network technologies, such as, 3G, 4G and 5G will promote rapid speed.

- Public Internet Access: The two sub-components of the public internet access program are the Common Service Centres and Post Offices as multi-service centres. Common Service Centres should be made viable and multi-functional endpoints for delivery of Government and business services.

- E-Governance: The system of e-governance will lead to transformation of every manual work into a complete automation system. The reformation of the system will take place in the following ways: online access to applications, i.e. availability of databases and information in electronic format, tracking of assignments in an effortless manner, interface between departments for superior production of work, and respond rapidly, analyse and provide solutions to persistent problems.

- e-Kranti: This e-kranti will completely focus upon digital technology, where education, health, farming, rights, financial and many more services will be delivered on a high bandwidth. Physical boundaries are no longer considered as limitations, when almost everyone and everything is easily accessible through digital technologies.

- Electronics Manufacturing: The electronics manufacturing is comprehensively recognized within the country with the assistance of digital technologies and skills. The empowerment of manufacturing through the internet of things will promote intellectual workshops that demonstrate the data driven operational excellence and decentralized production control systems within and beyond the physical factory walls.

- IT for Jobs: The Government is formulating measures to make provision of teaching and training to the youth for obtaining employment opportunities in the IT sector.

- Early Harvest: The Government is planning to set-up Aadhar Allowed Fingerprint Presence Program in all central Government places in New Delhi. A web-based application software system will allow online documenting of attendance and its watching is involved by all stakeholders.

- Information for All: Websites and mobile apps will convey the data and realistic participation and through social media. There is a connection between everything through virtual networks. The individuals are able to obtain access to information in a rapid manner and they are able to overcome the delays, caused due to waiting in queues.
Benefits of digital India program

The benefits of digital India program have been stated as follows: [2].

- Implementation of the Digital Locker System: The implementation of the digital locker system is facilitated through the digital India program. It leads to a decline in the paperwork by minimizing the utilization of physical documents as well as enabling e-sharing through registered repositories.

- Achievement of Online Goals: It ensures the achievement of both online goals, set by the Government. The online goals are mainly the ones, which are formulated by the Government to lead to effective growth and development in technologies and digital India.

- Submission of Documents: The individuals are able to submit the documents online, which reduces physical transformation of documents. For instance, when the individuals are required to submit applications or any documents to others, they make use of digital India program, which has led to decline in paperwork.

- Utilization of e-sign Framework: Citizens may digitally sign their documents online using e-sign framework. When individuals are filling up online applications, then normally they need to make use of e-sign framework to put their signatures.

- Availability of Health Care Services: Important health care services will be facilitated through digital programs. Tasks such as, online registration, taking appointments to consult the physicians, payment of fees, taking online diagnostic tests, blood check-up and so forth.

- Providing Benefits to the Beneficiaries: Benefits are provided to the beneficiaries through the National Scholarship Portal, by allowing the submission of application, verification process, sanction and disbursal.

- Delivery of Services: It is a huge platform, which facilitates the delivery of government services and private services to the citizens throughout the country. The individuals, who are not mobile are the ones, who benefit to a major extent through delivery of services.

- Bharat Net Program: Bharat Net Program is a high speed digital highway, which connects approximately 2,50,000 gram panchayats within the country. For the development of rural communities, and promoting digitalization, it is essential to establish a connection between gram panchayats and this is facilitated through digital India program.

- Plan of Outsourcing Policy: The plan of outsourcing policy is regarded as indispensable in promoting the digital India program.

- Acquisition of Information: Through utilization of technologies, the individuals throughout the country are able to access 
information regarding various areas. In order to carry out various tasks and functions in an appropriate manner, it is essential for the individuals to obtain access to the necessary information and attain the desired outcomes.

\section{Digital India and empowerment of rural communities}

Digital India has the primary objective of generating awareness among individuals, mainly residing in rural communities that making use of technologies and other benefits of the digital India program will lead to their empowerment. In rural communities, agriculture and farming practices are the primary occupations of the individuals. They have the major aim of generating productivity and profitability. For this purpose, particularly with advancements taking place, they aim to make use of modern, scientific and innovative methods in the production processes. In order to make efficient use of these methods, the rural individuals need to get enrolled in training centres and attain information in terms of these methods. Therefore, it has been found out that through utilization of technologies, the individuals are able to facilitate productivity. Apart from agriculture and farming practices, the rural individuals are also engaged in other tasks, such as, production of handicrafts, artworks, and so forth. Earlier they utilized traditional methods, but with the advent of technologies, they make use of modern and innovative methods in the production processes. Therefore, it can be stated that digitalization has led to empowerment of rural communities.

Empowerment of rural women is an important aspect, which needs to be taken into consideration in rural communities. In rural communities in some cases, women are not provided with equal rights and opportunities as their male counterparts and are discriminated against. The discriminatory treatment against women and girls have been observed in terms of acquisition of good quality education, employment opportunities, health care and medical facilities and providing other items such as, food, clothing, playthings etc. Research has indicated that there has been prevalence of comprehensive viewpoints that girls and women too should possess the basic literacy skills of reading, writing and arithmetic. As in the implementation of household responsibilities as well, these skills are regarded as indispensable. The digital India program has rendered a significant contribution in promoting empowerment opportunities among women. The women have generated awareness and recognized the significance of digitalization. They are augmenting their knowledge and information in terms of various areas and leading towards progression and empowerment. This program has facilitated access to medical and health care facilities for rural women.

Digital India is a plan that creates initiatives to establish connection between rural areas with the high-speed internet. It is an initiative to bring about transformations within the country into a digitally empowered economy. This program interlinks together a number of ideas and thoughts into a single comprehensive vision, so each of them is seen as a part of the larger objective. In the present existence, internet is rendering an important contribution in enriching the lives of the individuals, belonging to all communities, categories and backgrounds. The individuals are having internet in their mobile phones and are making use of it for multiple purposes. The internet is made use of for acquiring information in terms of various fields and concepts, making sales and purchases of items, communicating, paying bills, carrying out monetary transactions through internet banking systems and individuals usually make use of it to augment their knowledge and information, so they can carry out their job duties in an appropriate manner. Through the Digital India Program, the individuals have access to internet, even while travelling. Broadband highways have facilitated this task.

Another important aspect that has led to empowerment of rural communities is electronic commerce. Electronic commerce denotes eight comprehensive ranges of online business activities for products and services. E-commerce is regarded as the practice of electronic communications and digital information processing technologies in business transactions. Their main objective is to create, reform and redefine relationships for value creation and risk management between organizations and individuals. The project purposes to establish a connection between 2.5 lakh villages throughout the country. The major aspects, which promote connections are, broadband highways, public internet access, universal access to mobile connectivity, e-governance, e-kranti, information for all, electronic manufacturing, early harvest programs and IT for jobs. These are also regarded as the nine pillars of digital India. The cost of this project is valued at Rs. 1,13,000 crores. This indicates that there have been implementation of efforts in promoting digitalization of rural communities throughout the country. The Digital India Advisory Group will be chaired by the Cabinet secretary and monitored by the Prime Minister of India. Digital India Program has rendered a significant contribution in leading to up-gradation of rural communities [3]

Digital India is regarded as the flagship dream project of the government for the citizens of the country [3]. The individuals employed in different factories and industries such as, diamond industries, gem cutting, garment manufacturing, lock industries, silk weaving, and so forth used to make use of traditional methods. The utilization of traditional methods were time consuming and individuals had to work for long hours. On the other hand, the rate of productivity was low as compared to the productivity that was generated through utilization of technologies. With the initiation of measures and programs, the individuals are able to make use of technologies to augment productivity and profitability. The industries have also initiated training and development programs in which appropriate training is provided to the individuals in terms of utilization of technologies. Research has indicated that through the initiation of digital India program, the individuals are able to 
inculcate the traits of diligence, resourcefulness and conscientiousness among themselves and generate satisfactory outcomes within less amount of time.

The digital India program would also render a significant contribution in connecting various past and present projects, which would render a significant contribution in bringing India into the stage of global economies. It would also attract the investment in product manufacturing industries. Andhra Pradesh is the first state, who have opted for this implementation. The primary objective of this program is to lead to transformations in digital India. The individuals, belonging to all categories and backgrounds throughout the country should recognize the fact that digitalization would render an important contribution in promoting growth and development in an effectual manner. The digital India project purposes to transform the country into digital economy, which would increase the participation of rural and urban communities. This will ensure all government services and businesses are available everywhere and on any device that is accessible and secure. Digital India project bridges the gap between rural and urban communities [3]. This enables the rural individuals to overcome their backwardness and seclusion and be at par with the mainstream society.

\section{Estimated impact of digital India by 2019}

In the present existence, Information and Communications Technologies have brought about changes in the lives of the individuals in every respect and is also enabling the individuals to deliver services in the remote and backward regions of the country. The designing of ICT applications have been for the individuals, belonging to rural communities. Ministry of Rural Development in India has taken initiatives at various levels, by the ways of reinforcing the ICT infrastructure to make provision of opportunities, information and easy access of the rural development schemes to all citizens, particularly belonging to rural communities. Such developments have facilitated access to services and information in an economical manner in every scenario, where the cost of accessing information has been an impediment to agricultural labourers and farmers (Bhatia, \& Chhavi, 2016). The estimated impact of digital India has been taken into account in terms of three main aspects, economic, social and environmental and these have been stated as follows: [3].

- Economic Impact: It has been indicated by the experts that the digital India project could help Gross Domestic Product (GDP) up to $\$ 1$ trillion dollars by 2025 . It can assume a large part of the monetary factors, such as, GDP development, work age, work profitability, and development in the number of organizations. In accordance to the World Bank report, a 10 percent expansion in portable and broadband entrance increases the per capita GDP by 0.81 percent and 0.38 percent respectively. In India, there are 915 million remote endorsers and world's third largest internet advertise with nearly 259 million broadband clients. The future development of media transmission industry as far as number of supporters are relied upon to originate from the provincial zones as urban territories are immersed with tele-thickness of more than 160 percent.

- $\quad$ Social Impact: In order to live fulfilled lives, the individuals need access to various services. These include, health care, medical, insurance, banking, technologies, television, internet, education, training and so forth. Progressions have taken place in these areas to a major extent through the digital India project. Through ICT, individuals are getting engaged in number of tasks and activities. These include, generating information, making purchases and sales, paying bills, communicating and so forth. In addition, the individuals download apps on their mobile phones and get engaged in leisure and recreational activities. Acquiring good quality education and employment opportunities are important aspects, which the individuals primarily focus upon. For this purpose, they need to make use of internet to a major extent. Through internet, they are able to look for educational institutions and employment opportunities.

- Environmental Impact: As it has been stated above that when the individuals make use of modern and innovative strategies and methods in the production processes, they are able to lead to an increase in productivity and profitability. The utilization of technologies enables the individuals to carry out their tasks and activities in less time consuming and manageable manner. Through the use of ICT, the individuals are able to render an effective contribution in the administration and utilization of rare and non-inexhaustible assets. When the individuals are working with natural resources, they need to take into consideration the fact that they do not exploit them and curb various forms of pollution. It is vital for the individuals, primarily belonging to rural communities to curb environmental pollution as, they are dependent upon the natural resources to a major extent.

\section{Problems and challenges}

In rural communities, individuals encounter number of problems and challenges within the course of acquisition of technologies, and leading to enhancement. These have been stated as follows:

- Poverty: In rural communities throughout the country, poverty has been one of the major problems among individuals. Due to prevalence of the conditions of poverty, the individuals encounter problems and challenges in making ends meet. The individuals need to satisfy their basic requirements of food, clothing and shelter. In addition to these, they also need infrastructure, technologies, civic amenities, tools and equipment to carry out their tasks and activities satisfacto- 
rily and sustain better livelihoods opportunities. But conditions of poverty are regarded as the major impediments in sustaining their living conditions in a better way. Therefore, there is a need to formulate measures to alleviate the conditions of poverty and enriching livelihoods opportunities.

- Unemployment: In rural communities, there is a high rate of unemployment among individuals. Lack of awareness and literacy skills are the major causes for the high rate of unemployment. When the individuals are unemployed and struggle to make ends meet, they get effected psychologically. When the individuals are unable to achieve their desired goals and objectives, they experience psychological problems. Therefore, the psychological problems experienced by the individuals are the major impediments within the course of acquisition of technical skills. In order to provide solutions to this problem, there have been initiation of skills development programs, which have contributed effectively in enhancing the skills of the individuals, so they are able to sustain their living conditions in an appropriate manner.

- Illiteracy: In rural communities, the rate of illiteracy is high among individuals. There have been efforts made by the government to lead to an increase in the literacy rate. It needs to be ensured that the formulation of programs and measures generate positive outcomes. In rural communities, the rate of illiteracy is much higher as compared to urban communities. The main reason being, the system of education is not in a well-developed state. Therefore, there is a need to initiate measures to bring about improvements in the system of education. In order to enable the rural individuals to understand the significance of digital technologies, it is essential to impart them information regarding this area in schools. Apart from providing theoretical information, practical information also needs to be provided.

- Unawareness in terms of Information Technologies: In rural communities, the individuals do not possess adequate information regarding various aspects and even lack the basic literacy skills of reading, writing and arithmetic. Furthermore, their unawareness in terms of technologies are regarded as major barriers within the course of their progression. Hence, it is essential for the rural individuals to possess information in terms of information technologies. In India, there have been initiation of programs and schemes, such as, AGMARKNET, Bhoomi and so forth. The rural individuals are unable to make use of technologies, as they have not developed the capabilities among themselves [4].

- Different Languages: In India, throughout the country, individuals are different from each other on the basis of number of factors including caste, creed, race, religion, gender, ethnicity, educational qualifications, competencies, behavioural traits, personalities, occupations and socio-economic backgrounds. The individuals residing in different regions speak different languages. In rural communities too, individuals speak different languages. When their languages are different, it is apparent that they will not be able to acquire an efficient understanding of utilization of technologies and Digital India. The rural individuals are not well-equipped with English language. Hence, they need to learn to make use of technologies in a language, with which they are well-equipped.

- Hesitation to Change: Rural individuals usually are accustomed with their viewpoints and live their lives in accordance to their norms, values, and cultures. The elderly rural individuals, who have not been enrolled in schools before or have dropped out prematurely are hesitant and normally do not develop interest and motivation towards learning. When artisans and craftsmen are making use of traditional methods, they in some cases feel reluctant in making use of modern, scientific and innovative methods in their production processes. Research has indicated that rural individuals usually feel hesitant and apprehensive in making use of technologies. It is vital for the individuals to get engaged in great amount of practice in order to be well-equipped with technologies. Hence, their vulnerability towards technologies are regarded as barriers that have led to feelings of hesitation towards change.

- Infrastructure and Running Cost: There has been an increase in regional differences and social disparities [5]. It is difficult to connect all rural areas through the internet. At times, it is difficult to lay wires at these places. In rural and remote areas, there was not any provision of basic infrastructure and facilities, which would render an important contribution in establishing connections. The major infrastructural facilities that are required in rural areas to establish an internet connection are electricity and connectivity. Due to lack of these facilities, connections through internet have not been made possible (Srivastava, 2015). But there have been initiation of programs and schemes to make provision of electricity and other facilities throughout the country.

- Backwardness and Seclusion: In rural areas, the individuals are residing in the state of backwardness and seclusion. They interact within their own communities and remain isolated from the mainstream society. They are engaged in agriculture and farming practices and struggle to make ends meet. Due to backwardness and seclusion, they are unaware of modern and innovative methods that are essential to augment productivity. It is of utmost significance for individuals residing in rural communities to alleviate backwardness and seclusion and be at par with the mainstream society. There have been formulation of measures and programs, which 
have enabled them to alleviate backwardness and seclusion, generate awareness in terms of various aspects and communicate with other individuals as well.

- Traditional Viewpoints and Perspectives: In rural communities, the individuals normally possess traditional viewpoints and perspectives, which are regarded as the major challenges within the course of leading fulfilled lives. On the other hand, in urban communities, the individuals, belonging to various categories and backgrounds are making use of different types of technologies and generating information in terms of advancements taking place. Health of the individuals is an important aspect. In order to carry out tasks and activities in an appropriate manner, it is vital for the individuals to maintain good health. In order to take care of health care needs and requirements in an efficient manner, the individuals make visits to physicians and use medicines. On the other hand, in rural communities, the individuals make use of traditional methods and make use of medicinal plants and herbs to treat their illnesses and wounds. Therefore, it can be stated that possession of traditional viewpoints and perspectives is regarded as one of the major challenges within the course of making use of technologies.

- Gender Inequality: In some rural communities, girls and women were not regarded equal as their male counterparts. They were regarded as liabilities and individuals possessed the viewpoint that they should be trained in terms of implementation of household responsibilities and school education is not meant for them. Furthermore, they did not even believed in enhancing technical skills among them, as they would not be able to make use of them in their marital homes, mainly in the implementation of household responsibilities. On the other hand, males were considered as assets and they were enrolled in schools to acquire education and augment literacy skills. Therefore, due to gender inequality, women and girls experienced impediments within the course of acquisition of technical skills.

\section{Conclusion}

Digitalization of rural India will render a significant contribution in promoting growth and development of the nation. In rural areas, the individuals are residing in the state of backwardness, they possess traditional viewpoints and perspectives, are employed in the agricultural sector and farming practices and there is a high rate of illiteracy among them. Therefore, in order to promote development of rural individuals and communities, it is vital to make them recognize the significance of digitalization. There have been initiation of schemes and programs, which have an objective of generating awareness among the individuals regarding the significance of digital technology. The main aspects, which have recognized the significance of digitalization in rural communities are, broadband highways, universal mobile access, public internet access, e-governance, e-kranti, Electronics Manufacturing, IT for jobs, early harvest and information for all. The benefits of the digital India program are, implementation of the digital locker system, achievement of online goals, submission of documents, utilization of e-sign framework, availability of health care services, providing benefits to the beneficiaries, delivery of services, Bharat Net Program, plan of outsourcing policy and acquisition of information.

The estimated impact of digital India by 2019 has been taken into account in terms of three main aspects, economic, social and environmental. In rural communities, the individuals encounter number of problems and challenges within the course of promoting digitalization and enhancing their overall livelihoods opportunities. These are, poverty, unemployment, illiteracy, unawareness in terms of information technologies, different languages, hesitation to change, infrastructure and running cost, backwardness and seclusion, traditional viewpoints and perspectives and gender inequality. The individuals, who aim to promote digitalization of rural communities need to conduct analysis of the areas, which are the major impediments. Furthermore, they need to provide effective solutions, so that rural individuals are able to recognize the significance of digitalization to a large extent and work effectively towards sustenance of better livelihoods opportunities.

\section{Bibliography}

1. Bhatia A and Chhavi K. "Rural Development through E-Governance Initiatives in India”. IOSR Journal of Business and Management (2016): 61-69.

2. Kumar T., et al. "Role of Digital India in Rural Areas". International Journal of Advance Engineering and Research Development (2017): 1-4.

3. Luvy. "Impact of Digital India by 2019". International Journal of Scientific and Engineering Research 9.4 (2018): 1285-1288.

4. Srivastava N. "E-Governance in Rural India". International Journal of Computer Science and Information Technologies 6.1 (2015): 741-744.

5. India Rural Development Report 2012-2013. IDFC Rural Development Network (2013).

Volume 3 Issue 9 September 2019 (C) All rights are reserved by Radhika Kapur. 